\title{
Gender Differences in Pedestrian Perception and Satisfaction on the Walkability of Kuala Lumpur City Center
}

\author{
Ahmad Kamil Arshad ${ }^{1, a}$, Noor Iza Bahari ${ }^{2}$, Wardati Hashim² and A.G. Abdul Halim ${ }^{3}$ \\ ${ }^{1}$ Institute for Infrastructure Engineering and Sustainability Management, Universiti Teknologi Mara, 40450 Shah \\ Alam, Malaysia \\ ${ }^{2}$ Faculty of Civil Engineering, Universiti Teknologi Mara, 40450 Shah Alam, Malaysia \\ ${ }^{3}$ Faculty of Civil and Environmental Engineering, Universiti Tun Hussein Onn Malaysia, 86400 Parit Raja, Johor, \\ Malaysia
}

\begin{abstract}
The quality of built environment usually influences the walkability of a city. This is because each pedestrian walk differently on different type of facilities or built environment provided to them. This paper aims to investigate whether gender differences influences the pedestrian perception and satisfaction level at three sidewalks located within the Kuala Lumpur City Center by means of questionnaire survey. A total of 317 pedestrians were involved in the questionnaire survey at the three different sidewalk locations. The result shows significant differences in mean satisfaction value between male and female pedestrians. Female pedestrian give lower satisfaction value for overall travel experience at Jalan Tuanku Abdul Rahman but higher satisfaction value at Petaling Street and Bukit Bintang compared to male pedestrian. Overall, the satisfaction level was rated between acceptable to satisfactory regardless of gender differences. Improvements should be made for the safety parameter because both male and female pedestrian gives lowest satisfaction level in that area.
\end{abstract}

\section{Introduction}

Walkability can be defined as to what extend does the build environment or the surrounding environment could encourage and support walking [1]. Walkability is usually linked to the quality of the built environment and connected by the quality of the pedestrian environment. The condition of the sidewalk plays an important role in increasing the level of walkability of the built environment. The sidewalk path context and quality of sidewalk network are adequate predictors to walkability that has the ability to affect the walking likelihood and increased walkability in a city [1-4]. Lack of walkable elements within the sidewalk can negatively affect pedestrian walking behavior [5]. Safe walking environment will also influenced pedestrian activities positively [6]. The tendency of people to walk more often and farther increased in an environment with high sidewalk qualities $[2,7]$.

Walking does not only give benefits in terms of personal health but also give benefits to the country through economic development in commercial areas with high pedestrian movement. A walkable city could act as an alternative solution in reducing traffic congestion with low impact towards the environment [8]. Due to these reasons, the Malaysia Government (through Dewan

\footnotetext{
${ }^{\text {a }}$ Corresponding author : drahmadkamil@salam.uitm.edu.my
} 
Bandaraya Kuala Lumpur) and the private sector have cooperated to construct and upgrade the existing pedestrian network in Kuala Lumpur. This long term development includes a total of 45KM length of covered (including elevated) pedestrian network throughout Kuala Lumpur city [9]. In order to promote and facilitate pedestrianisation, enhancement projects such as sidewalk widening, provision of safer road crossing, landscape treatment and high kerb obstacle removal were initiated [10].

However, pedestrian perception and preference on the sidewalk facilities during their walking journey may also be closely related to socio-demographic characteristic and personal factors such as gender, age and transportation mode choice [11]. These characteristics differences give influence on the pedestrian travel behavior, thus influencing their perception and travel decision [12]. In order to create a desirable walking environment that promotes walking, pedestrian are the most appropriate group to be surveyed as they are the daily user of the facilities. This paper attempts to investigate whether gender differences influences the pedestrian perception and satisfaction level for sidewalks located within the Kuala Lumpur City Centre. The findings could assists the planer, local authorities and facilities provider in providing optimum pedestrian facilities that consider local pedestrian travel preferences and characteristics rather than using existing rules of thumb and research findings from other countries with different cultural background and characteristics.

\section{Methodology}

The major steps involved for this study include study area selection, paper-based on-street questionnaire survey and data analysis. Three study areas located within Kuala Lumpur City Center that have highest pedestrian volume of 100 pedestrian/hour or higher (determined by extrapolation of 15 minutes manual count) were selected for this study. Questionnaire surveys were then distributed to 100 or more respondents at each location to assess the pedestrian perception and satisfaction level during their journey at each sidewalk. Random sampling method was used in distributing the questionnaire survey to increase the generalisability [13]. The collected data were transformed from qualitative data to quantitative data during data analysis by giving weighted rating number to each level of satisfaction (qualitative data) given by the respondent to facilitate the understanding of the data obtained during the survey.

\subsection{Study area}

The Kuala Lumpur Structure Plan 2020 has identified City Center Commercial (CCC) zone that is located within the Kuala Lumpur City Centre. CCC is a commercial zone that promotes a broad range of commercial activities to be conducted within walking distance, this provide the highest potential in supporting Kuala Lumpur's economic growth [10]. CCC within Kuala Lumpur City Centre was divided into three different districts namely Tuanku Abdul Rahman (TAR), Golden Triangle and Old City Centre. Three locations were selected within each CCC district which is Jalan Tuanku Abdul Rahman (TAR), Jalan Bukit Bintang and Petaling Street as shown in Figure 1 and Figure 2. The facilities available in these areas include public transport system, shopping complexes, education centres and business centres within walking distance, thus offering a broad range of pedestrian activities including shopping, leisure, working and commuting transit.

\subsection{On-street questionnaire survey}

Paper-based on-street questionnaire survey method was carried out on each sidewalk. The survey was carried out during afternoon peak hour on working weekdays. Random sampling technique was used in selecting respondent. A total of at least 100 pedestrians using the sidewalk facilities were participated in the survey for each sidewalk location. The parameters surveyed include land use and accessibility, safety, path facilities / amenities, aesthetic / pleasurability and overall travel experience. 


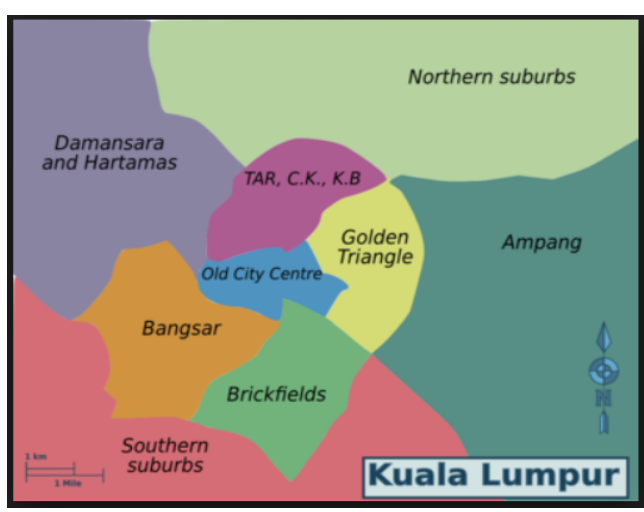

Figure 1. Kuala Lumpur District [14].

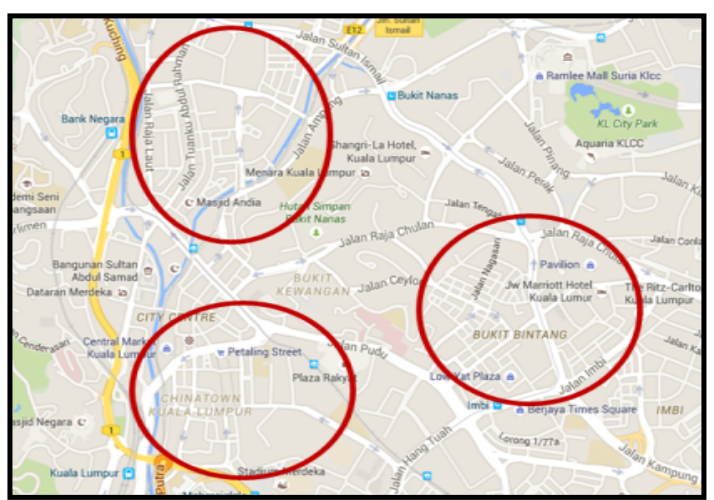

Figure 2. Selected study area in Kuala Lumpur [15].

\subsection{Data analysis}

To facilitate data analysis, the qualitative data collected was transformed into quantitative data using simplified weighted factor analysis method. Total Weighted Score (TWS) and Average Weighted Score (AWS) are calculated using Equation (1) and Equation (2) respectively. There are 10 scale of agreement involved in counting the weighted score as shown in Table 1. Weighted factor calculation example is also shown in Table 1. By setting the score to zero (0) as the borderline or acceptable satisfaction level, any positive (+ve) value calculated indicates that the respondents are satisfied, whereas negative (-ve) value calculated indicates that the respondents are dissatisfied with the existing sidewalk condition. The mean satisfaction rating was then determined using the same Likert scale of agreement in Table 1 to assess the pedestrian satisfaction level according to gender differences. Lastly, statistical analysis that involves reliability test was performed on the data set using SPSS Software to check the validity of the result.

Total Weighted Score, TWS $=\sum(W F \times N)_{1}+(W F \times N)_{2}+\ldots+(W F \times N)_{n}$

Average Weighted Score, AWS = (Total Weighted Score $) /($ Number of Respondents, N)

where: WF $=$ Weighing Factor; $\mathrm{N}=$ Number of Respondents; $\mathrm{n}=$ Scale of Agreement; TWS $=$ Total Weighted Score; AWS = Average Weighted Score.

Table 1. Weighing factor and weighted score calculation example.

\begin{tabular}{|l|c|c|c|c|}
\hline Level of Satisfaction & $\begin{array}{c}\text { Scale of } \\
\text { Agreement, } \mathbf{n}\end{array}$ & $\begin{array}{c}\text { Weighing } \\
\text { Factor ,WF }\end{array}$ & $\begin{array}{c}\text { No. of } \\
\text { Respondent, N }\end{array}$ & $\begin{array}{c}\text { Weighted } \\
\text { Score, WS }\end{array}$ \\
\hline Not satisfied at all & 1 & -5 & 2 & -10 \\
\hline Very dissatisfied & 2 & -4 & 4 & -16 \\
\hline Moderately dissatisfied & 3 & -3 & 0 & 0 \\
\hline Slightly dissatisfied & 4 & -2 & 6 & -12 \\
\hline Somewhat dissatisfied & 5 & -1 & 3 & -3 \\
\hline Somewhat satisfied & 6 & 1 & 6 & 6 \\
\hline Slightly satisfied & 7 & 2 & 5 & 10 \\
\hline Moderately satisfied & 8 & 3 & 0 & 0 \\
\hline Very Satisfied & 9 & 4 & 3 & 12 \\
\hline Completely satisfied & 10 & 5 & 1 & 5 \\
\hline Total Weighted Score & & & 30 & -8 \\
\hline Average Weighted Score & & & & -0.267 \\
\hline
\end{tabular}




\section{Results and Discussion}

The results are presented in two different sections. The first section used simplified average weighted factor analysis to assess pedestrian perception on the existing sidewalk condition. The second section used SPSS software to calculate mean satisfaction level according to gender.

\subsection{Pedestrians' perception on the existing sidewalk condition}

A total of 317 pedestrians were involved in the questionnaire survey at the three different sidewalk locations. Table 2 shows the results for pedestrian travel experience. Jalan TAR obtained the highest score (AWS =1.3379) which is higher than the average for all areas surveyed (AWS =1.0387). This is followed by Bukit Bintang (AWS = 1.0612) and Petaling Street which was rated the lowest by the pedestrians (AWS $=0.6788$ ). The AWS for other parameters on pedestrian perception is shown in Figure 3. Based on the overall results, the pedestrian rated the existing sidewalks in the range between somewhat satisfied to slightly satisfied based on the Likert Scale as shown in Table 1. However, all the pedestrians surveyed agreed that the safety parameter is slightly acceptable, as the score approached zero for all sidewalks especially at Petaling Street (0.259 AWS value).

Table 2. Average weighted score for overall travel experience by road.

\begin{tabular}{|l|c|c|c|c|c|c|c|c|}
\hline \multirow{2}{*}{ Criteria } & \multicolumn{2}{|c|}{ Jalan TAR } & \multicolumn{2}{c|}{ Bukit Bintang } & \multicolumn{2}{c|}{ Petaling Street } & \multicolumn{2}{c|}{ TOTAL } \\
\cline { 2 - 9 } & TWS & AWS & TWS & AWS & TWS & AWS & TWS & AWS \\
\hline $\begin{array}{l}\text { Overall Travel } \\
\text { Experience }\end{array}$ & 172 & 1.6863 & 158 & 1.3621 & 61 & 0.6559 & $\mathbf{3 9 1}$ & $\mathbf{1 . 2 5 7 2}$ \\
\hline $\begin{array}{l}\text { Pathway / Sidewalk } \\
\text { Condition }\end{array}$ & 144 & 1.3981 & 114 & 0.9828 & 64 & 0.7033 & $\mathbf{3 2 2}$ & $\mathbf{1 . 0 3 8 7}$ \\
\hline Crossing & 137 & 1.3301 & 115 & 1.0000 & 59 & 0.6413 & $\mathbf{3 1 1}$ & $\mathbf{1 . 0 0 3 2}$ \\
\hline Sidewalk Amenities & 127 & 1.2451 & 110 & 0.9565 & 60 & 0.6452 & $\mathbf{2 9 7}$ & $\mathbf{0 . 9 5 8 1}$ \\
\hline Personal Safety & 103 & 1.0000 & 39 & 0.3362 & 18 & 0.1957 & $\mathbf{1 6 0}$ & $\mathbf{0 . 5 1 4 5}$ \\
\hline $\begin{array}{l}\text { Adjacent Traffic/Driver's } \\
\text { behavior }\end{array}$ & 92 & 0.9020 & 62 & 0.5391 & 52 & 0.5591 & $\mathbf{2 0 6}$ & $\mathbf{0 . 6 6 4 5}$ \\
\hline Aesthetics and Amenities & 165 & 1.6176 & 192 & 1.6696 & 78 & 0.8478 & $\mathbf{4 3 5}$ & $\mathbf{1 . 4 0 7 8}$ \\
\hline Accessibility & 157 & 1.5243 & 189 & 1.6435 & 110 & 1.1828 & $\mathbf{4 5 6}$ & $\mathbf{1 . 4 6 6 2}$ \\
\hline Mean AWS & & 1.3379 & & 1.0612 & & 0.6788 & & $\mathbf{1 . 0 3 8 7}$ \\
\hline
\end{tabular}

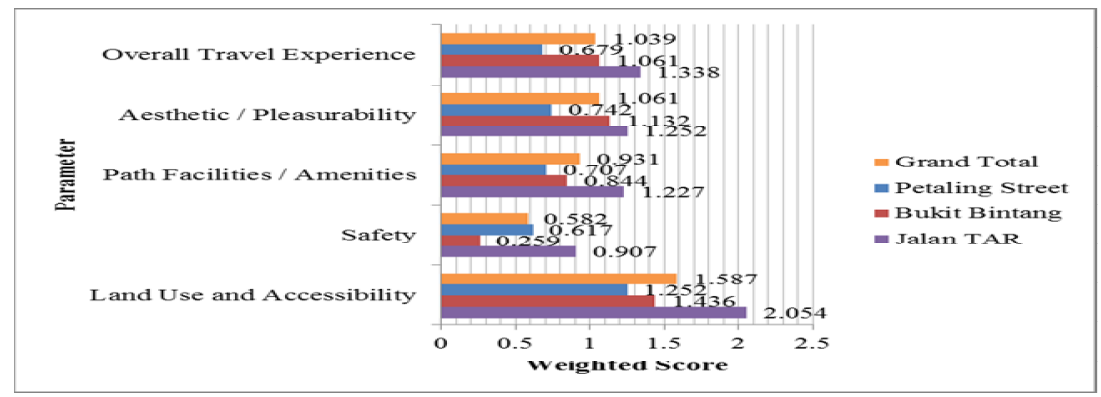

Figure 3. Mean of average weighted score for each parameter.

\subsection{Pedestrian satisfaction level by gender difference}

From the total of 317 respondents, $45 \%$ were male respondent and 55\% were female respondent. The gender split for each sidewalk location is shown in Fig. 4. There is significance difference that can be observed in the male and female satisfaction level. Female pedestrian gave almost similar mean satisfaction level value for all sidewalks with Bukit Bintang receiving the highest value (6.53), 
followed by Petaling Street (6.36) and Jalan Tar (6.31). On the other hand, male pedestrian rated Jalan TAR as the most satisfied sidewalk and Petaling Street as the least satisfied with high difference in mean satisfaction value of 7.04 and 5.72 respectively. However, Bukit Bintang obtained almost similar mean satisfaction value for both male and female respondents. Both male and female pedestrian agreed that all sidewalks in the study location were lacking in terms of safety which can be seen by the lowest mean value of 5.89 and 5.98 obtained in this area for male and female pedestrians respectively. Overall, male pedestrian satisfaction level of sidewalk arrangement were in line or similar to the results calculated using average weighted score for overall travel experience where Jalan TAR is the most satisfied, followed by Bukit Bintang and Petaling Street.

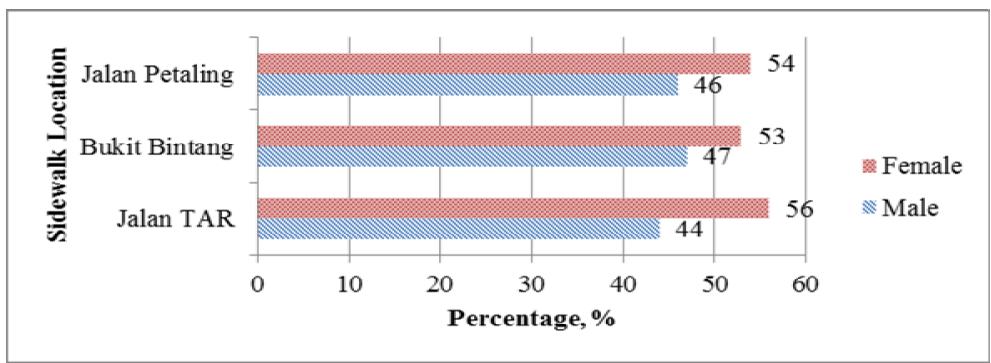

Figure 4. Gender split.

Table 3. Pedestrian mean satisfaction level by gender and road.

\begin{tabular}{|l|c|c|c|c|c|c|c|c|}
\hline \multirow{2}{*}{ Criteria } & \multicolumn{2}{|c|}{ Jalan TAR } & \multicolumn{2}{c|}{ Bukit Bintang } & \multicolumn{2}{c|}{ Petaling Street } & \multicolumn{2}{c|}{ Total All } \\
\cline { 2 - 9 } & Male & Female & Male & Female & Male & Female & Male & Female \\
\hline Overall Travel Experience & 7.24 & 6.70 & 6.50 & 6.76 & 5.67 & 6.40 & 6.49 & 6.63 \\
\hline $\begin{array}{l}\text { Pathway / Sidewalk } \\
\text { Condition }\end{array}$ & 7.02 & 6.40 & 6.19 & 6.42 & 5.83 & 6.26 & 6.35 & 6.36 \\
\hline Crossing & 7.09 & 6.28 & 6.02 & 6.56 & 5.70 & 6.35 & 6.26 & 6.40 \\
\hline Sidewalk Amenities & 6.93 & 6.23 & 6.17 & 6.42 & 5.81 & 6.20 & 6.30 & 6.29 \\
\hline Personal Safety & 6.71 & 6.05 & 5.63 & 5.95 & 5.35 & 5.94 & 5.89 & 5.98 \\
\hline $\begin{array}{l}\text { Adjacent Traffic/Driver's } \\
\text { behavior }\end{array}$ & 6.91 & 5.79 & 5.85 & 6.10 & 5.70 & 6.18 & 6.14 & 6.02 \\
\hline Aesthetics and Amenities & 7.11 & 6.66 & 6.70 & 7.11 & 5.86 & 6.54 & 6.58 & 6.79 \\
\hline Accessibility & 7.31 & 6.38 & 6.77 & 6.94 & 5.81 & 7.04 & 6.65 & 6.78 \\
\hline Average & $\mathbf{7 . 0 4}$ & $\mathbf{6 . 3 1}$ & $\mathbf{6 . 2 3}$ & $\mathbf{6 . 5 3}$ & $\mathbf{5 . 7 2}$ & $\mathbf{6 . 3 6}$ & $\mathbf{6 . 3 3}$ & $\mathbf{6 . 4 1}$ \\
\hline
\end{tabular}

\subsection{Statistical analysis}

The reliability test was carried out using SPSS Software to calculate Cronbach's Alpha values. Table 4 shows that Cronbach's Alpha values obtained were between 0.812 and 0.954 . The high value of Cronbach's Alpha coefficient indicates greater internal consistency of the item on the scale [16] and that the result is valid for analysis [17].

Table 4. Statistical analysis using reliability test.

\begin{tabular}{|c|l|c|}
\hline \multirow{2}{*}{ No } & \multicolumn{1}{|c|}{ Section } & Reliability Test \\
\cline { 3 - 3 } & & Cronbach's Alpha \\
\hline 1 & Land Use and Accessibility & 0.894 \\
\hline 2 & Safety & 0.928 \\
\hline 3 & Path Facilities / Amenities & 0.880 \\
\hline 4 & Aesthetic / Pleasurability & 0.812 \\
\hline 5 & Overall Travel Experience & 0.954 \\
\hline
\end{tabular}




\section{Conclusion}

The respondents rated the existing sidewalk between acceptable to slightly satisfied for all sidewalk locations since there was no negative AWS value obtained for all the parameters. The safety parameter obtained the lowest AWS value for all sidewalks. Female pedestrian gave almost similar rating for all sidewalks. Male pedestrian gave same rating arrangement with AWS analysis arrangement. Improvements should be made for the safety parameter because both male and female pedestrian gives lowest satisfaction level in that area. The safety areas to be improved include safety while using the sidewalk, adjacent traffic, crossing safety, personal safety against crime and stray animals, safety while using the sidewalk during night and rainy days.

\section{Acknowledgement}

The author would like to express gratitude to Faculty of Civil Engineering, UiTM and to all volunteers in completing the survey for this study. This research is funded by Ministry of Science, Technology and Innovation (MOSTI) under eScience Fund.

\section{References}

[1] M. Southworth, Designing the walkable city, J. Urban Plan. Develop., 131(4), 246-257, (2005).

[2] F. Jaskiewicz, Pedestrian level of service based on trip quality, Transportation Research Circular E-C019, National Research Council, Washington, (2000).

[3] K.R. Rahaman, J.M. Lourenco and J.M. Viegas, Perceptions of pedestrians and shopkeepers in European medium-sized cities: Study of Guimaraes, Portugal J. Urban Plan. Develop., 138(1), 26-34, (2012).

[4] S. Lotfi and J. Koohsari, Neighborhood walkability in a city within a developing country, J. of Urban Plan. Develop., 137(4), 402-408, (2011).

[5] S. Shamsuddin, N.R. Abu Hassan and S.F.I. Bilyamin, Walkable environment in increasing the liveability of a city, Procedia - Social and Behavioral Sciences, 50, 167 - 178, (2012).

[6] J. Zakaria and N. Ujang, Comfort of walking in the city center of Kuala Lumpur, Procedia Social and Behavioral Sciences, 170, 642-652, (2015).

[7] C.E. Kelly, M.R. Tight, F.C. Hodgson and M.W. Page, A comparison of three methods for assessing the walkability of the pedestrian environment, J. Trans. Geo., 19(6), 1500-1508, (2011).

[8] N.I. Bahari, A.K. Arshad and Z. Yahya, Assessing the pedestrians' perception of the sidewalk facilities based on pedestrian travel purpose, IEEE 9th International Colloquium on Signal Processing and its Applications, (2013).

[9] Information on http://app.kwpkb.gov.my/greaterklkv/entrypoint-project-pedestrian

[10]Information on http://www.dbkl.gov.my/pskl2020/english/urban_design_and_landscape

[11]P.P. Koh and Y.D. Wong, Comparing pedestrians' needs and behaviours in different land use environments, J. Trans. Geo., 26, 43-50, (2013).

[12]M.G. Boarnet and S. Sarmiento, Can land-use policy really affect travel behaviour?: A study of the link between non-work travel and land-use characteristics, Urban Studies, 35(7), 1155 - 1169 , (1998).

[13] S.M. Tseng, Correlations between external knowledge and the knowledge chain as impacting service quality, Journal of Retailing and Consumer Services, 19, 429-437, (2012).

[14] Information on https://en.wikivoyage.org/wiki/Kuala_Lumpur

[15]Information on https://www.google.com.my/maps/place/Kuala+Lumpur

[16]J.A Gliem, R.R. Gliem, Calculating, interpreting, and reporting cronbach's alpha reliability coefficient for likert-type scales, Midwest Research to Practice Conference in Adult, Continuing, and Community Education, 1992, 82-88, (2003).

[17]D. George and P. Mallery, SPSS for Windows Step by Step, Allyn and Bacon, Boston, (2003). 